\title{
Soluble polymethylsilsesquioxane synthesis in organic solvents
}

\author{
(C) Vladimir Yu. Chuklanov, ${ }^{1}{ }^{+}$Kirill V. Smirnov, ${ }^{1}$ and Natalia V. Chuklanova ${ }^{2}$ \\ ${ }^{1}$ Vladimir State University Named after A.G. and N.G. Stoletovs. Gorkogo St., 87. Vladimir, 600000. Russia. \\ Phone:+7 (4922) 47-96-19; (4922)47-97-53.E-mail: chukhlanov11@gmail.com; kirillv.smirnov@yandex.ru \\ ${ }^{2}$ Ivanovo State Polytechnic University. Sheremetevsky Ave., 21. Ivanovo, 153000. Ivanovo Region. Russia. \\ Phone: +7 (904)030-08-61.E-mail:vladsilan@mail.ru
}

\begin{abstract}
*Supervising author; ${ }^{+}$Corresponding author
Keywords: synthesis, polymethylsilsesquioxane, methyltrichlorosilane, synthesis, Box-Wilson planning method.
\end{abstract}

\begin{abstract}
In this work the synthesis process of soluble polymethylsilsesquioxane that is a valuable prepolymer in the production of ceramic products, high-temperature protective coatings for high-speed aircraft, primary product for the formation of LEDs and other elements of microelectronics was studied. The synthesis was carried out from methyltrichlorosilane in a binary system of polar and non-polar solvent under the water action. The possibility of polymethylsilsesquioxane with a sufficiently high seepage at atmospheric pressure synthesis was shown. The resulting compound was analyzed. The presence of polymethylsilsesquioxane bonds in the polymer was identified by infrared Fourier spectroscopy on the Bruker Tensor 27 spectrometer. The resulting polymer has all the characteristics of polymethylsilsesquioxane. This is confirmed in particular by the presence of a characteristic wide band over the range by $1050-1100 \mathrm{~cm}^{-1}$ in the spectrum. To find out the optimal synthesis conditions and obtain the maximum yield of polymethylsilsesquioxane, the experiment was planned using the Box-Wilson planning method. The influence of temperature, reaction time and nature of solvents on the yield of polymethylsilsesquioxane was also studied. The optimal conditions for the synthesis were found out. The highest yield of polymethylsilsesquioxane was observed at $10{ }^{\circ} \mathrm{C}$ with a 6 hours synthesis duration. When the temperature increased to $30{ }^{\circ} \mathrm{C}$, a partial decrease in the polymer yield was observed. It is assumed that at a high temperature and a significant time of the process, a partial decrease in the yield of polymethylsilsesquioxane associated with a decrease in the soluble fraction begins to occur.
\end{abstract}

\section{References}

[1] N.B. Kondrashova, V.A. Valtsifer, V.N. Strelnikov, V.Ya. Mitrofanov, and S.A. Uporov. Magnetic characteristics of mesoporous materials $0.1 \mathrm{NiO}-1 \mathrm{SiO}_{2}$ as influenced upon by introduction of trialkoxysilane additives during synthesis. Butlerov Communications. 2015. Vol.41. No.1. P.159-162. DOI: $10.37952 / R O I-j b c-01 / 15-41-1-159$

[2] A.A. Kapustina, V.V. Libanov, A.A. Rumina, N.P. Shapkin, and T.I. Akimova. Study of the interaction of tin(II and IV) and titanium(IV) oxides with polyphenylsiloxane by mechanochemical activation. Butlerov Communications. 2018. Vol.56. No.12. P.118-125. DOI: 10.37952/ROI-jbc-01/18-56-12-118

[3] A.V. Varaksin, V.L. Lisin, V.A. Kostilev, L.I. Leontiev, E.V. Ignatieva, A.B. Shubin, and S.A. Petrova. Application of composite agglomerates based on $\mathrm{WC}$ and $\mathrm{TiC}$ produced by electrochemical technology for preparation of antiwear coatings by direct laser cladding. Butlerov Communications. 2016. Vol.48. No.10. P.14-22. DOI: 10.37952/ROI-jbc-01/16-48-10-14

[4] V.Yu. Chukhlanov, N.N. Smirnova, N.V. Chukhlanova, and E.E. Mastalygina. Syntactic foams based on hollow ceramic microspheres and binder of oligomethylsilsesquioxane. Butlerov Communications. 2018. Vol.56. No.10. P.107-111. DOI: 10.37952/ROI-jbc-01/18-56-10-107 